\title{
Thrombolytic treatment (alteplase; rt-PA) in acute massive pulmonary embolism and cardiopulmonary arrest
}

This article was published in the following Dove Press journal:

Drug Design, Development and Therapy

12 June 2014

Number of times this article has been viewed

\author{
Adem Dirican' \\ Sevket Ozkaya ${ }^{2}$ \\ Ali Ekber Atas $^{3}$ \\ Esra Kayahan Ulu ${ }^{4}$ \\ Ilknur Kitapci ${ }^{5}$ \\ Ferah $\mathrm{Ece}^{2}$ \\ 'Department of Pulmonary Medicine, \\ Medical Park Samsun Hospital, \\ Samsun, Turkey; ${ }^{2}$ Department of \\ Pulmonary Medicine, Faculty of \\ Medicine, Bahçeșehir University, \\ Istanbul, Turkey; ${ }^{3}$ Department of \\ Cardiology, Medical Park Samsun \\ Hospital, Samsun, Turkey; ${ }^{4}$ Department \\ of Radiology, Medical Park Samsun \\ Hospital, Samsun, Turkey; ${ }^{5}$ Department \\ of Intensive Care Unit, Medical Park \\ Samsun Hospital, Samsun, Turkey
}

Abstract: Patients with pulmonary thromboembolism (PE) often decompensate suddenly, and once hemodynamic compromise has developed, mortality is extremely high. Currently, thrombolytic therapy for PE is still controversial. We retrospectively evaluated 34 patients with PE between January 2010 and December 2013 in the Department of Pulmonary Medicine, Medical Park Samsun Hospital, Samsun, Turkey. The demographic and disease characteristics of patients who received thrombolytic treatment were retrospectively analyzed. The female to male ratio was 19/15 and the mean age was $63.1 \pm 13.2$ years. PE diagnosis was made using echocardiography $(64.7 \%)$ or contrast-enhanced thorax computed tomography with echocardiography (32.4\%). Twenty-two (64.7\%) patients went into the cardiopulmonary arrest due to massive PE and 17 (50\%) patients recovered without sequelae. Eleven (32.4\%) patients were diagnosed with massive PE during cardiopulmonary arrest with clinical and echocardiographic findings. Alteplase (recombinant tissue plasminogen activator [rt-PA]) was administered during cardiopulmonary resuscitation (CPR) and four $(36.3 \%)$ patients responded and survived without sequelae. The complications of rt-PA treatment were hemorrhage in five (14.7\%) patients and allergic reactions in two (5.9\%) patients. There was no mortality due to rt-PA treatment complications. In conclusion, mortality due to massive PE is much more than estimated and alteplase can be used safely in patients with massive PE. This thrombolytic treatment was not associated with any fatal hemorrhage complication. If there is any sign of acute PE, echocardiography should be used during cardiopulmonary arrest/ instability. Alteplase should be given to patients with suspected massive PE.

Keywords: massive pulmonary embolism, thrombolytic treatment, rt-PA, cardiopulmonary arrest, resuscitation, mortality, hemorrhage

\section{Introduction}

Pulmonary embolism (PE) is a common disorder and an important cause of morbidity and mortality. PE occurs in approximately 650,000 patients annually in the US, of whom approximately 300,000 die. $^{1-3} \mathrm{PE}$ often arise from thrombus originating in the deep venous system of the lower extremities or pelvis. A blood clot dislodges and is swept into the pulmonary circulation and lodges in a pulmonary artery. If the clot is large enough to obstruct large vessels in the lung, it can cause hemodynamic instability, along with right ventricular (RV) failure, and possibly death. However, $5 \%-10 \%$ of patients with PE have an unstable hemodynamic status and go into shock, and have an almost $60 \%$ higher mortality rate compared with patients without these characteristics. ${ }^{4,5}$ Currently, thrombolytic therapy for PE is still controversial. Only patients with acute massive PE (ie, those at the highest risk of immediate death) are eligible for fibrinolytic therapy if no contraindications are present. There are not enough data on recombinant
Correspondence: Sevket Ozkaya Department of Pulmonary Medicine, Faculty of Medicine, Bahçeșehir University, Çırağan Caddesi Osmanpașa Mektebi Sokak No: 4-6, 34353 Beșiktaș, Istanbul, Turkey

Mob+90532474 I3 09

Email ozkayasevket@yahoo.com 
tissue plasminogen activator (rt-PA; alteplase) in patients with massive PE. We aimed to evaluate the results of massive PE and thrombolytic treatment in patients with hemodynamic instability due to massive PE.

\section{Patients and methods}

We retrospectively evaluated patients with PE between January 2010 and December 2013 in the Department of Pulmonary Medicine, Medical Park Samsun Hospital, Samsun, Turkey. The demographic and disease characteristics of patients who received thrombolytic treatment were retrospectively analyzed. The diagnosis of PE and patient selection for thrombolytic treatment were decided on using the following criteria: 1) patients $>17$ years with onset of symptoms suggestive of acute massive PE; 2) massive PE defined as acute PE with sustained hypotension (systolic blood pressure $<90 \mathrm{mmHg}$ for at least 15 minutes or requiring inotropic support, not due to a cause other than PE, such as arrhythmia, hypovolemia, sepsis, or left ventricular [LV] dysfunction), pulselessness, or persistent profound bradycardia (heart rate $<40 \mathrm{bpm}$ with signs or symptoms of shock). In addition, acute RV dilation, hypokinesis, and acute pulmonary arterial hypertension with paradoxal movement of the interventricular septum on echocardiography were added as criteria for thrombolytic treatment in patients with hemodynamic instability and/or cardiopulmonary arrest; and 3) $\mathrm{PE}$ is confirmed with contrast-enhanced thorax computed tomography (CT) in appropriate patients.

\section{Treatment plan}

The rt-PA (Actilyse ${ }^{\circledR}$; Boehringer Ingelheim, Ingelheim, Germany) is administered as a $10 \mathrm{mg}$ bolus via central line and $90 \mathrm{mg}$ continuous infusion over 2 hours. All of the patients were monitored for measurements of heart rate; systolic, diastolic, and mean systemic blood pressures; and oxygen saturation with a pulse oximeter.

The study was performed in accordance with the ethical principles in the Good Clinical Practice (GCP) guidelines, applicable local regulatory requirements, and the protocol was approved by local ethics review boards. All the patients read the patient information form about the study procedure and written informed consent was obtained.

\section{Results}

A total of 34 patients were diagnosed and treated with rt-PA because of massive PE. The characteristics of the patients and treatment results are presented in Table 1 . The female to male ratio was $19 / 15$ and the mean age was $63.1 \pm 13.2$ years.
Table I Characteristics of patients and treatment results

\begin{tabular}{ll}
\hline Characteristics & $\mathbf{n}(\%)$ \\
\hline Age-year & \\
Mean & $63.1 \pm 13.2$ \\
Minimum-maximum & $27-84$ \\
Sex & \\
Female & $19(55.9)$ \\
Male & $15(44.1)$ \\
Risk factor & \\
No & $5(14.7)$ \\
Surgery & $13(38.2)$ \\
Immobilization & $16(47.1)$ \\
Diagnosis & \\
Echocardiography & $23(64.7)$ \\
Echocardiography with radiology & $1 \mathrm{II}(32.4)$ \\
Cardiopulmonary arrest & \\
No & $12(35.3)$ \\
Yes & $22(64.7)$ \\
Drug on resuscitation & \\
Yes & $\mathrm{II}(32.4)$ \\
Alive & $4(36.3)$ \\
Complication & \\
No & $27(79.4)$ \\
Hemorrhage & $5(14.7)$ \\
Other (allergy) & $2(5.9)$ \\
Mortality due to complication & 0 \\
Survival & \\
Alive & $17(50)$ \\
\hline & $17(50)$ \\
\hline
\end{tabular}

PE diagnosis was made using echocardiography (64.7\%) or contrast-enhanced thorax CT with echocardiography (32.4\%) (Figures 1,2,3, and 4). Twenty-two (64.7\%) patients went into cardiopulmonary arrest due to massive PE and $17(50 \%)$ of total patients recovered without sequelae. The most common finding was tachycardia in all patients with massive PE. Eleven (32.4\%) of patients were diagnosed with massive PE during cardiopulmonary arrest with clinical and echocardiographic findings. rt-PA was administered during cardiopulmonary resuscitation (CPR) and four (36.3\%) patients responded and survived without sequelae. The complications of rt-PA treatment were hemorrhage in five $(14.7 \%)$ patients and allergic reactions in two $(5.9 \%)$ patients. There was no mortality due to any complication of the rt-PA treatment.

\section{Discussion}

$\mathrm{PE}$ ranges in severity from acute massive PE to acute pulmonary infarction to acute embolism without infarction to multiple emboli. Only patients with acute massive PE (ie, those at the highest risk of immediate death) are eligible for fibrinolytic therapy if no contraindications are present. In the International Cooperative Pulmonary Embolism 


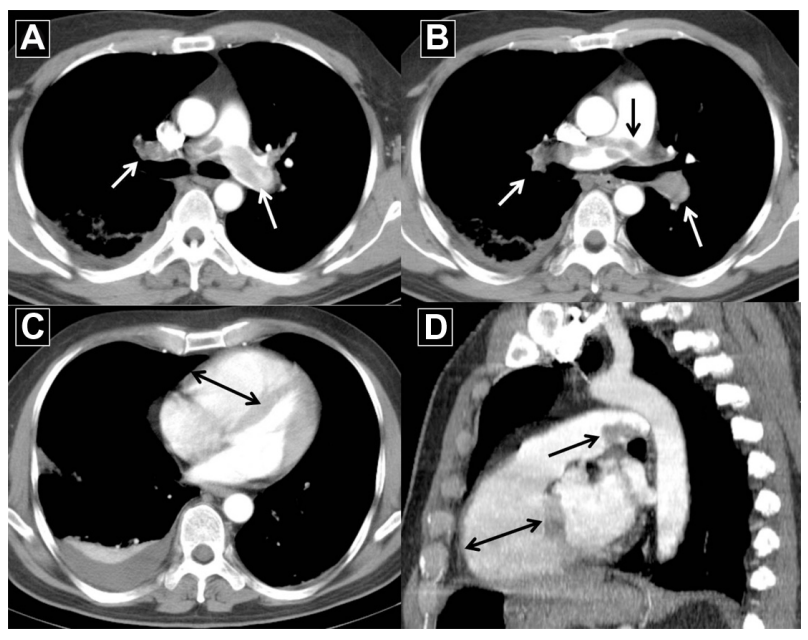

Figure I A 48-year-old man presented with intractable tachycardia, acute dyspnea, and systemic hypotension (arrows).

Notes: The radio contrast-enhanced thorax CT shows massive filling defects both at the bifurcation and "saddle" pulmonary embolism in the right and left pulmonary arteries (A, B, and D). Also shown is the dilated right atrium and right ventricle with a shift towards the left ventricle of the interventricular septum (C and $\mathbf{D})$. Abbreviation: $\mathrm{CT}$, computed tomography.

Registry (ICOPER) of 2,454 consecutive patients from seven countries, $4.2 \%$ had massive PE. In the US, approximately 150,000 patients per year are diagnosed with acute PE, resulting in thousands of recognized deaths annually from massive PE. Many additional deaths occur each year in the US as a result of undiagnosed massive PE that is mistaken

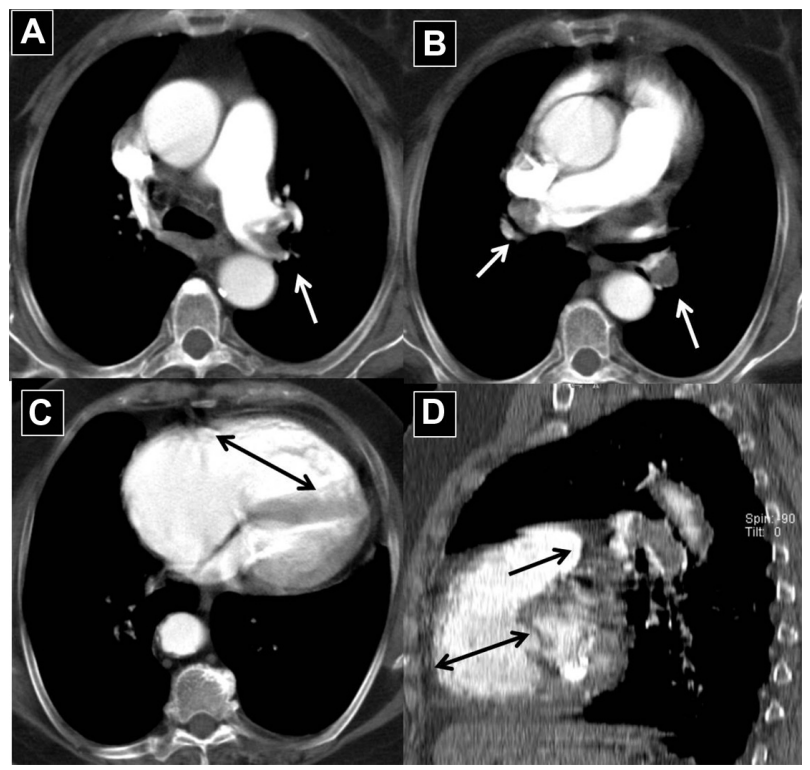

Figure 2 A 80-year-old woman admitted to the emergency service due to syncope (arrows).

Note: The radio contrast-enhanced thorax CT shows the presence of substantial thrombus burden in the left and right pulmonary arteries (A, B, and $\mathbf{D})$ with dilated right atrium and right ventricle with a shift towards the left ventricle of the interventricular septum (C and D).

Abbreviation: CT, computed tomography.

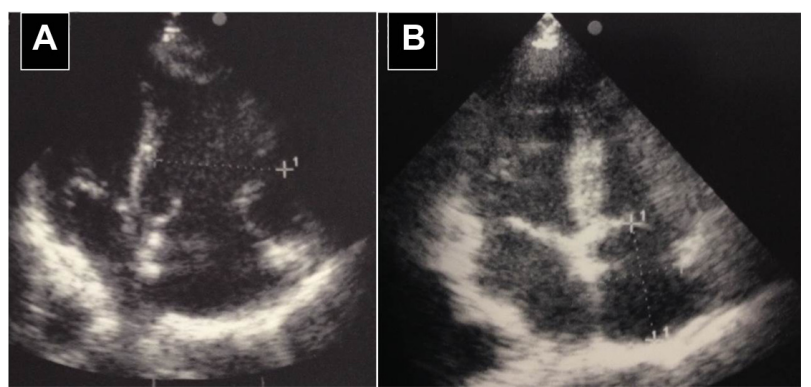

Figure 3 A 43-year-old woman admitted to the hospital presenting with acute dyspnea, tachycardia, and hypotension.

Notes: The echocardiography images show the marked (dotted lines) acute enlargement of the right atrium and right ventricle with hypokinetic right ventricular wall, interventricular septal shift towards the left ventricle and tricuspid valvular insufficiency with pulmonary hypertension (A). Normal right heart function was seen after 24 hours of treatment with alteplase (B).

for acute myocardial infarction or ventricular arrhythmia. ${ }^{5-7}$ The most experience with thrombolytic agents in $\mathrm{PE}$ is with streptokinase and urokinase, which are first-generation plasminogen activators. Tissue-type plasminogen activator (t-PA) is a second-generation thrombolytic agent that has high affinity for fibrin and is activated by fibrin. Alteplase was the first rt-PA and is identical to native t-PA. In vivo, t-PA is synthesized and made available by cells of the vascular endothelium. It is the physiologic thrombolytic agent responsible for most of the body's natural efforts to prevent excessive thrombus propagation. In 1986, Goldhaber et al reported that 2-6 hours of rt-PA was effective in achieving angiographically proven clot lysis in acute PE. ${ }^{8}$

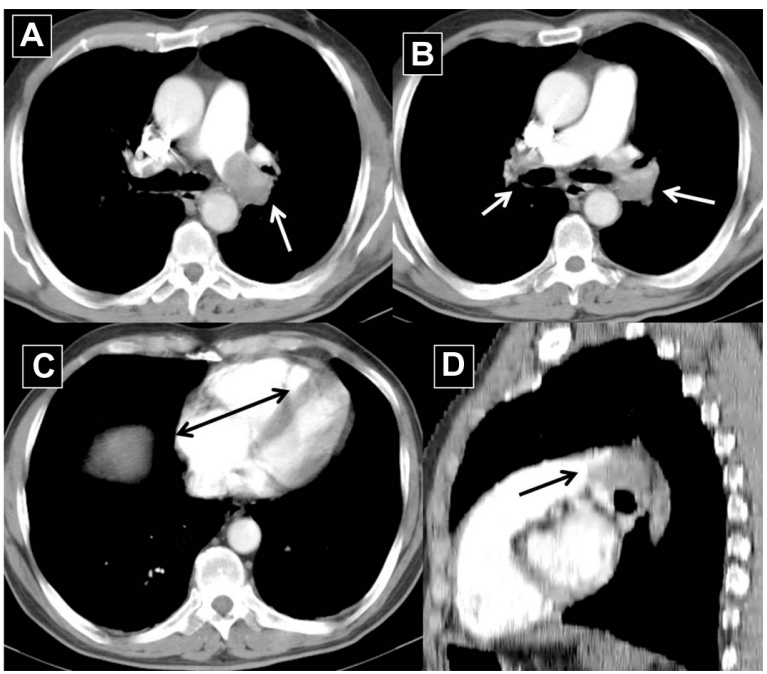

Figure 4 A 58-year-old man admitted to hospital with acute dyspnea, hypotension, and hypoxia (arrows).

Note: The radio contrast-enhanced thorax CT showing total obstruction with a thrombus in the right and left pulmonary arteries ( $\mathbf{A}$ and $\mathbf{B}$ ) with enlargement of the right heart and a shift towards the left ventricle of the interventricular septum (C and D).

Abbreviation: CT, computed tomography. 
If available, a bedside transthoracic echocardiogram should be obtained as soon as diagnosis of massive PE is suspected. When we suspect massive PE in hemodynamically unstable patients, we perform an echocardiography as the first diagnostic tool. The echocardiogram is not only useful for substantiating the diagnosis by confirming RV dysfunction and dilatation but can also exclude diagnoses that may mimic PE such as aortic dissection, pericardial tamponade, or acute myocardial infarction. We performed the echocardiography in $23(64.7 \%)$ patients as a diagnostic tool, of which 11 (32.4\%) of them were in cardiopulmonary arrest. The echocardiogram can also diagnose complications of PE such as right heart thrombi or even show thrombus protruding into the left atrium via a patent foramen ovale or atrial septal defect. In patients with poor image quality of the RV or in those who undergo CPR, transesophageal echocardiography may be used. In patients who can be stabilized with fluids, pressors, or mechanical ventilation, a contrast-enhanced chest CT will demonstrate filling defects in the main or lobar pulmonary arteries, as well as RV enlargement on the reconstructed CT four-chamber view. ${ }^{9-11}$ Although systemic fibrinolysis is not worth the risk in all patients with acute PE, it is recommended as standard, first-line treatment in patients with massive PE. The preferred fibrinolytic agent is alteplase as a $100 \mathrm{mg}$ continuous 2-hour infusion, as in our patients. In an overview of the five randomized controlled trials that included patients with massive PE, fibrinolysis reduced the risk of death or recurrent PE by $55 \% .^{12,13}$

Active CPR is clearly not a contraindication for thrombolytic therapy. Studies that aim to identify causal factors in out-of-hospital cardiac arrest show that $50 \%-70 \%$ of cases are attributable to either massive PE or acute myocardial infarction. ${ }^{14,15}$ Although cardiac arrest initiated by intracoronary thrombosis in situ is different from the mechanisms associated with PE, thrombolysis has proved to be an effective treatment strategy for both these diseases. ${ }^{16,17}$ Recent clinical case reports and small case series have suggested that thrombolysis during cardiac arrest can contribute to hemodynamic stability and is associated with improvements in long-term survival and functional recovery, as seen in our four $(36.3 \%)$ patients.

In an overview of eleven randomized controlled trials of fibrinolysis versus heparin among 748 unselected PE patients, major bleeding complications occurred in $9.1 \%$ of fibrinolysis-treated and $6.1 \%$ of heparin-treated patients. Major bleeding also occurs more often in patients with massive rather than non-massive $\mathrm{PE}$, both with fibrinolysis plus heparin and with heparin alone. In an overview of the five randomized controlled trials that included patients with massive PE, fibrinolysis doubled the risk of major bleeding: $22 \%$ of fibrinolysis versus $12 \%$ of heparin patients $(6,18)$. We noted the complications of rt-PA treatment were hemorrhage in $5(14.7 \%)$ patients and allergic reactions in $2(5.9 \%)$ patients. There was no mortality due to complication of rt-PA treatment.

Ruiz-Bailén et al described the outcomes using thrombolysis during CPR of patients in cardiorespiratory arrest (CA) caused by fulminant PE (FPE) ${ }^{18} \mathrm{rt}$-PA was administered during usual CPR maneuvers when there was a strong suspicion of FPE, as in our patients. Four of the six patients survived and remain symptom free. The thrombolysis was not associated with any fatal complications. They concluded that early thrombolysis during CPR maneuvers for CA apparently caused by an FPE may reduce the mortality rate among these patients.

Also, we noted that the most common finding was intractable tachycardia in all patients with massive PE. We suggested that the bradycardia and intractable tachycardia with systemic hypotension should be included in the criteria of thrombolytic treatment in patients with massive PE.

In conclusion, mortality due to massive PE is much more than estimated and alteplase can be safely used in patients with massive PE. Thrombolytic treatment was not associated with any fatal hemorrhage complication. If there is any sign of acute PE, echocardiography should be used during cardiopulmonary arrest/instability, and alteplase should be given to patients with suspected massive PE.

\section{Author contributions}

$\mathrm{AD}, \mathrm{SO}, \mathrm{AEA}$, and IK managed and treated the patients; EKU analyzed the radiologic images; and FE consulted with the patients and revised the article. All authors contributed toward data analysis, drafting and revising the paper, and agree to be accountable for all aspects of the work.

\section{Disclosure}

The authors report no conflicts of interest in this work.

\section{References}

1. Horlander KT, Mannino DM, Leeper KV. Pulmonary embolism mortality in the United States, 1979-1998: an analysis using multiple-cause mortality data. Arch Intern Med. 2003;163(14):1711-1717.

2. Burge AJ, Freeman KD, Klapper PJ, Haramati LB. Increased diagnosis of pulmonary embolism without a corresponding decline in mortality during the CT era. Clin Radiol. 2008;63(4):381-386.

3. Kearon C, Kahn SR, Agnelli G, Goldhaber S, Raskob GE, Comerota AJ; American College of Chest Physicians. Antithrombotic therapy for venous thromboembolic disease: American College of Chest Physicians Evidence-Based Clinical Practice Guidelines (8th Edition). Chest. 2008; 133(Suppl 6):454S-545S. 
4. Darze ES, Latado AL, Guimarães AG, et al. Incidence and clinical predictors of pulmonary embolism in severe heart failure patients admitted to a coronary care unit. Chest. 2005;128(4):2576-2580.

5. Goldhaber SZ, Visani L, De Rosa M. Acute pulmonary embolism: clinical outcomes in the International Cooperative Pulmonary Embolism Registry (ICOPER). Lancet. 1999;353(9162):1386-1389.

6. Kucher N, Goldhaber SZ. Management of massive pulmonary embolism. Circulation. 2005;112(2):e28-e32.

7. Stein PD, Hull RD, Ghali WA, et al. Tracking the uptake of evidence: two decades of hospital practice trends for diagnosing deep vein thrombosis and pulmonary embolism. Arch Intern Med. 2003;163(10): 1213-1219.

8. Sors H, Pacouret G, Azarian R, Meyer G, Charbonnier B, Simonneau G. Hemodynamic effects of bolus vs 2-h Infusion of alteplase in acute massive pulmonary embolism. A randomized controlled multicenter trial. Chest. 1994;106(3):712-717.

9. Torbicki A, Galié N, Covezzoli A, Rossi E, De Rosa M, Goldhaber SZ; ICOPER Study Group. Right heart thrombi in pulmonary embolism: results from the International Cooperative Pulmonary Embolism Registry. J Am Coll Cardiol. 2003;41(12):2245-2251.

10. Pruszczyk P, Torbicki A, Kuch-Wocial A, Szulc M, Pacho R. Diagnostic value of transoesophageal echocardiography in suspected haemodynamically significant pulmonary embolism. Heart. 2001;85(6):628-634.

11. Schoepf UJ, Kucher N, Kipfmueller F, Quiroz R, Costello P, Goldhaber SZ. Right ventricular enlargement on chest computed tomography: a predictor of early death in acute pulmonary embolism. Circulation. 2004;110(20):3276-3280.
12. Wan S, Quinlan DJ, Agnelli G, Eikelboom JW. Thrombolysis compared with heparin for the initial treatment of pulmonary embolism: a meta-analysis of the randomized controlled trials. Circulation. 2004;110(6):744-749.

13. Büller HR, Agnelli G, Hull RD, Hyers TM, Prins MH, Raskob GE. Antithrombotic therapy for venous thromboembolic disease: the Seventh ACCP Conference on Antithrombotic and Thrombolytic Therapy. Chest. 2004;126(Suppl 3):401S-428S

14. Silfvast T. Cause of death in unsuccessful prehospital resuscitation. J Intern Med. 1991;229(4):331-335.

15. Spaulding CM, Joly LM, Rosenberg A, et al. Immediate coronary angiography in survivors of out-of-hospital cardiac arrest. $N$ Engl J Med. 1997;336(23):1629-1633.

16. Indications for fibrinolytic therapy in suspected acute myocardial infarction: collaborative overview of early mortality and major morbidity results from all randomised trials of more than 1000 patients. Fibrinolytic Therapy Trialists' (FTT) Collaborative Group. Lancet. 1994;34(8893):311-322.

17. Arcasoy SM, Kreit JW. Thrombolytic therapy of pulmonary embolism: a comprehensive review of current evidence. Chest. 1999;115(6) 1695-1707.

18. Ruiz-Bailén M, Aguayo-de-Hoyos E, Serrano-Córcoles MC, et al. Thrombolysis with recombinant tissue plasminogen activator during cardiopulmonary resuscitation in fulminant pulmonary embolism. A case series. Resuscitation. 2001;51(1):97-101.
Drug Design, Development and Therapy

\section{Publish your work in this journal}

Drug Design, Development and Therapy is an international, peerreviewed open-access journal that spans the spectrum of drug design and development through to clinical applications. Clinical outcomes, patient safety, and programs for the development and effective, safe, and sustained use of medicines are a feature of the journal, which

\section{Dovepress}

has also been accepted for indexing on PubMed Central. The manuscript management system is completely online and includes a very quick and fair peer-review system, which is all easy to use. Visit http://www.dovepress.com/testimonials.php to read real quotes from published authors.

Submit your manuscript here: http://www.dovepress.com/drug-design-development-and-therapy-journal 